\title{
Analysis of the influence of train timetable on energy consumption on the metro line
}

\author{
Stawomir Barański ${ }^{1, *}$, and Marcin Steczek ${ }^{1}$ \\ ${ }^{1}$ Lodz University of Technology, Institute of Electrical Power Engineering, Faculty of Electrical, Electronic, Computer and Control \\ Engineering, ul. Stefanowskiego 18/22, 90-924, Łódź, Poland
}

\begin{abstract}
The latest technical solutions provide new opportunities for reducing energy consumption in electrified transport systems. The basic solution is to eliminate vehicles based on resistor start-up system and replace them with vehicles equipped with semiconductor based converter propulsion system (choppers and voltage source inverters). This type of drive also allows to recover energy (recuperation) from train braking, which is repeated very often case of metro lines. The problem is to find the receiver for this energy while the vehicle is braking. Large opportunities are also available when using various types of energy storage devices: stationary installed on the side of traction line and mobile ones used on-board the traction vehicles. Choosing the type of energy storage device for operating conditions, their capacity and the location of installation are complex optimization processes. This type of solution involves significant financial input, which reimbursement is spread over a long period of time. Therefore, it seems rational to seek solutions with limited financial outlay. This paper presents a solution analysis of adjusting the timetable and timeshifts between vehicle streams on the metro line to increase the efficiency of energy recovery of regenerative braking vehicles. This operation will reduce the amount of energy consumption by vehicles from the traction substations. The results presented in the paper were obtained by computer simulation of operation on the first line of the Warsaw subway, assuming that there was no energy storage devices and traction substations were operating without recuperation of the energy to the power system.
\end{abstract}

\section{Introduction}

Electric means of urban transport are characterized by relatively low power of used vehicles and high volume of traffic. Under such conditions, the use of recuperative braking in used vehicles can achieve its highest efficiency, up to $40 \%[1,2]$. The metro system is characterized by the highest regularity of traffic due to complete separation from the road traffic. This makes the traffic in the metro system easier to control due to its predictability, in comparison with e.g. the tram traffic. This can provide more potential for being able to affect some parameters that influence the efficiency of the braking vehicle's electrical energy recovery. In a system without subsystem energy recovery or possibility of storage in the reservoirs, the problem solution comes down to the proper synchronization of braking vehicles with vehicles that accelerate. The problem of energy consumption by electric means of transport is a determinant of their profitability and therefore requires continuous research [3]. In [4] it is reported that systems ATR (Automatic Train Regulation) and AOC (Adaptive Optimal Control) are being developed. These systems are designed to maximize the throughput of subway lines and minimize energy consumption.

Implementation of mentioned algorithms, however, requires full cooperation with both, the signalling system and whole structure of additional devices that support the work of entire the system. Another method of reducing energy consumption may be the optimization of the driving technique for a single train $[5,6]$. In the article, a method of limiting energy consumption in the metro system is presented, based on the regulation of time intervals between vehicles entering the metro line. The main advantage of the proposed method is that, for implementation, it does not require any additional financial investment in infrastructure. Some aspects of the reduction of the energy consumption with low investment costs in the underground transportation was described in [8] but the technique proposed in this paper was not taken into account. The proposed method can be used on older lines that have been in operation for a long time, where no future investment in infrastructure is expected.

\section{Simulation object description}

The subject of analysis is the metro line I in Warsaw, section A1 Kabaty - A11 Politechnika. The test section consists of eleven stops and six traction substations. Traction substations operated in this section do not provide the possibility of reclaiming the energy recovered by vehicle's recuperative braking in the electrical system (no inverters at the substation). In examined configuration energy storage is not possible, in result, it must be used by

* Corresponding author: slawomir.baranski@p.lodz.pl 
another vehicle at the time of its recovery. Otherwise it will be dispersed in braking resistors of a braking vehicle. Electricity is supplied to vehicles by means of a third rail. The line uses longitudinal sectioning with one cross connection as part of the section at the point where the third rail is supplied with power. The significant equipment used on the analysed line, from the point of the research, is the system of automatic speed limitation SOP2. Mentioned system, developed at the Electrical Traction Department of the Technical University of Lodz [7], belongs to the group of Automatic Train Protection (ATP) systems, whose primary task is to ensure safe train operation by the driver or ATO (automatic train operation) system. The operation of this system significantly influences train traffic, especially in the case of very dense traffic, by limiting the maximum travel speed. The maximum vertical profile of the route is $25 \%$ while the accepted length of the platforms is $120 \mathrm{~m}$.

\section{Simulation software description}

The software allows to simulate the operation of the metro line, the following simplifications have been adopted: traffic is carried out with the equal traction vehicles, there are no branches of the line, the traffic resistance assumed for the simulation calculations take into account travelling through tunnels.

The unitary resistance of motion of the modelled vehicle was described using the following equation:

$$
w=w_{0}+\frac{1}{k}\left[\frac{v}{10}\right]^{2}+i
$$

where:

$$
\begin{array}{ll}
i & \text { - profile of the track, } \\
k & \text { - coefficient of motion resistance, } \\
v & \text { - velocity. }
\end{array}
$$

The $\mathrm{w}_{0}$ is the coefficient dependent from the state of the vehicle. When the vehicle is under influence of pulling or breaking force the $\mathrm{w}_{0}$ equals $2\left(w_{0}=2\right)$. When traction and breaking force are equal zero then $w_{0}$ can be described with following formula:

$$
w_{0}=2 \cdot\left(1+\frac{g l}{g}\right)
$$

where:

$$
g l \text { - weight of motor car, }
$$

$g$ - weight of whole vehicle.

The available acceleration for the vehicle for specified operating point can be calculated:

$$
a=\left(\frac{f}{g}-\frac{w}{1000}\right) \cdot \frac{9.81}{\alpha}
$$

where:

$$
\begin{array}{ll}
f & \text { - tractive force, } \\
w & \text { - unitary motion resistance, } \\
\alpha & \text { - coefficient of rotating mass. }
\end{array}
$$

The operation of the simulation software consists in determining, at the assumed time step (uploaded as one of the output data), the locations of the trains, the voltages on their current collector, the electrical currents they take from the traction network and the load currents of the traction substations. If the value of the time step is sufficiently small, the above instantaneous values of voltages and currents can be considered as the average values for the period of the calculation step.

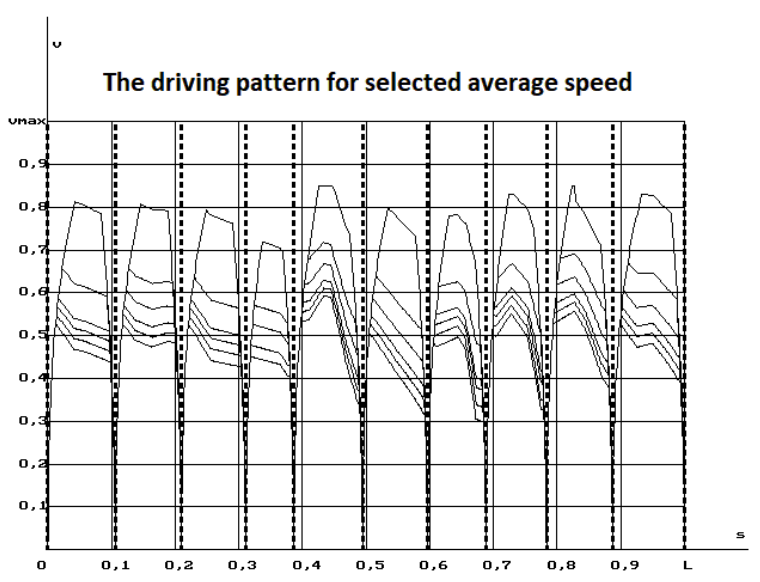

Fig. 1. Determining the energy-efficient theoretical drive with fixed average speed.

In the model adopted for the simulation of the line work, three basic functional blocks can be identified: the timetable block, the theoretical pass block and the electrical power calculation block, where the last two blocks work with a specific "feedback loop" - the theoretical pass block provides data to the electrical power calculation block (the location of trains on the line and currents taken from or off the network by them), the electrical power calculation block forwards data to theoretical pass block, with the information concerning current values of voltages on the e.m.u. current collector.

The timetable block controls the movement of the trains on the section of the line for which the simulation is carried out. Block accomplishes above mentioned task by fulfilling four basic functions by :

- positioning trains on the line at the beginning of the simulation;

- allowing new trains at the beginning of the line at the correct time;

- controlling traffic safety by ensuring adequate distances between trains on the route, depending on the current train velocities;

- withdrawing trains from traffic at the end of the line. From the point of view of constructing the timetable block line in the model, the way the SOP system works out the permissible speeds for particular trains is very important. This system assumes the division of lines into fixed block lengths of different distances, while the permissible speed of the train at a given distance depends on the number of free block lengths before the train and amounts to: $87 \mathrm{~km} / \mathrm{h}$ at four or more free block lengths, $76 \mathrm{~km} / \mathrm{h}$ at three block lengths, $60 \mathrm{~km} / \mathrm{h}$ at two and 37 $\mathrm{km} / \mathrm{h}$ with one free block lengths in front of the train. When the preceding block is busy, the train is stopped. The model assumes that the delayed train will always try 
to reduce the delay by extending the driving distance under current, if its delay is not too considerable. In case of any delay of more than half of the scheduled interval between trains, which is already a significant disturbance in the uniformity of traffic on the line and which is difficult to compensate by extending the drive under current, the timetable for the whole line is rebuilt in such a way that most delayed train becomes the reference point for the new timetable - in this new layout, the remaining trains will reduce the speed accordingly, thereby ensuring that the trains are evenly distributed on the route. Figure 2 shows a simplified algorithm for the simulation program.

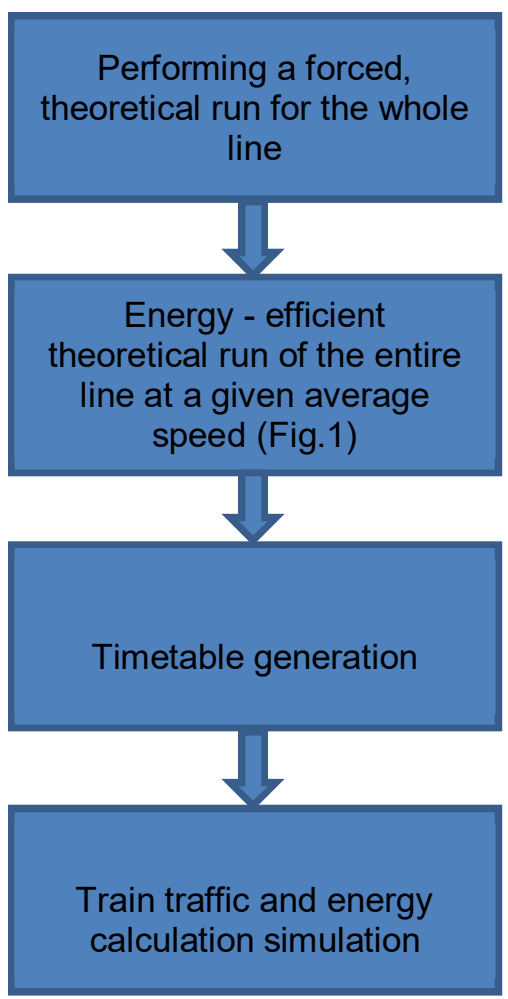

Fig. 2. Subsequent and simplified simulation steps.

After the data upload, that describes the line and the trains running on it, software performs a forceful run of the entire line in order to determine the possible average speed of passing through the line. Subsequently, after inputting given, average speed value, the theoretical energy-efficient passage is determined, that allows the given average speed to be reached with minimal energy consumption (Fig. 1). For executed run, a timetable, prepared with the given parameters, is being generated, and accordingly, software starts the simulation of train traffic on the line, at the same time performing the calculations to determine energy consumption during the simulation.

\section{Simulation results}

The maximum achievable train speed on the line at $30 \mathrm{~s}$ stop at the station was $39.5 \mathrm{~km} / \mathrm{h}$. However, a passage with such an average speed is only possible at relatively high intervals between successive trains. For a shorter succession time, the ATP system limits the maximum speed, hence the achievable average speed is also lower. As the traffic simulation was conducted for $90 \mathrm{~s}$ and 120 $\mathrm{s}$, the average speeds were assumed to be on 30 to $36 \mathrm{~km} / \mathrm{h}$ level. The cumulative results of the simulation are presented in the 3D graph in Fig. 3 and Fig. 4.

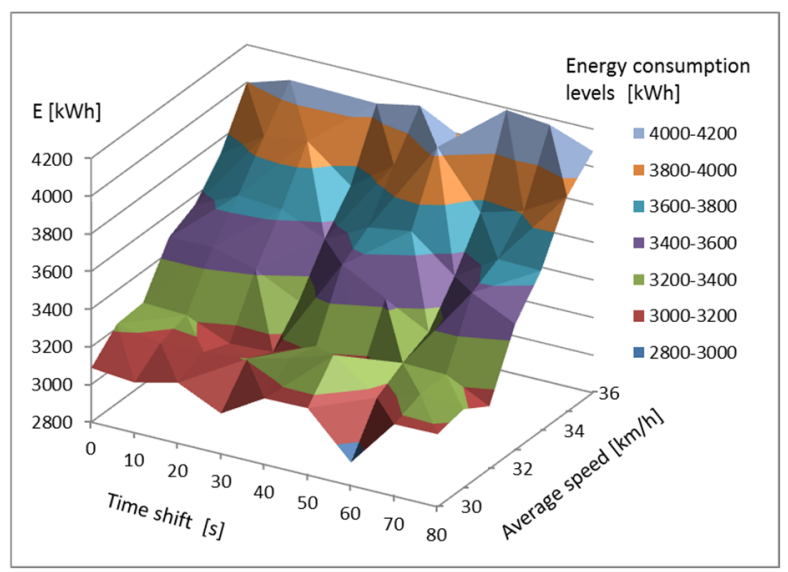

Fig. 3. Energy consumption for passages with a 90 seconds succession, with a change in the average speed and time shift between traffic directions.

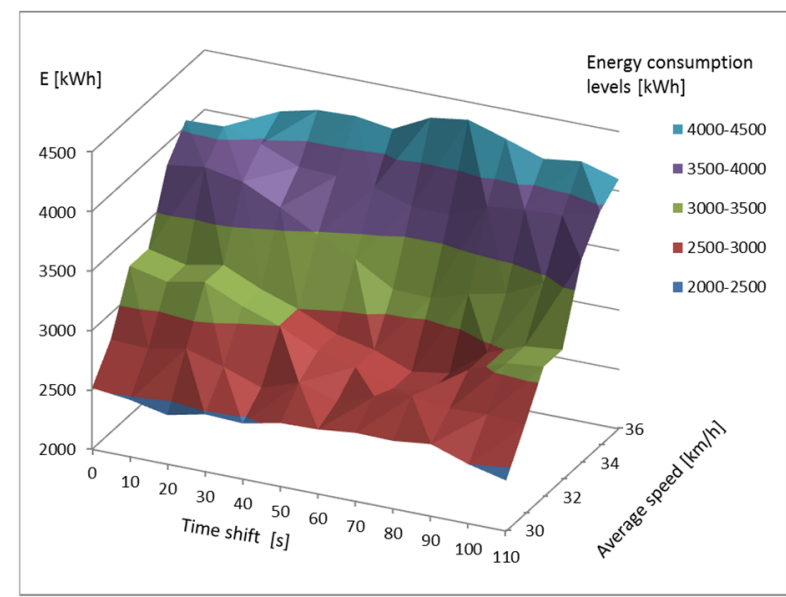

Fig. 4. Energy consumption for passages with a 120 seconds succession, with a change in the average speed and time shift between traffic directions.

The next figures shows the separated line graphs of energy consumption during driving with a succession time of 90 and 120 seconds for the average speed of the train running from 30 to $36 \mathrm{~km} / \mathrm{h}$ and the change of the shift time between the traffic directions on the line from 0 to $80 \mathrm{~s} \mathrm{(Fig.} \mathrm{5)} \mathrm{and} 0$ to $110 \mathrm{~s} \mathrm{(Fig.} \mathrm{6).}$ 


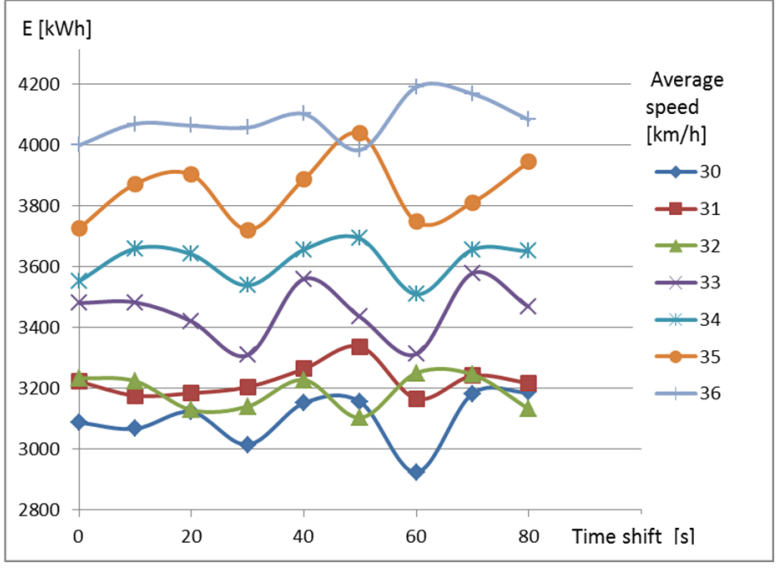

Fig. 5. Graph of energy consumption for traffic on the line with the succession time of 90 seconds.

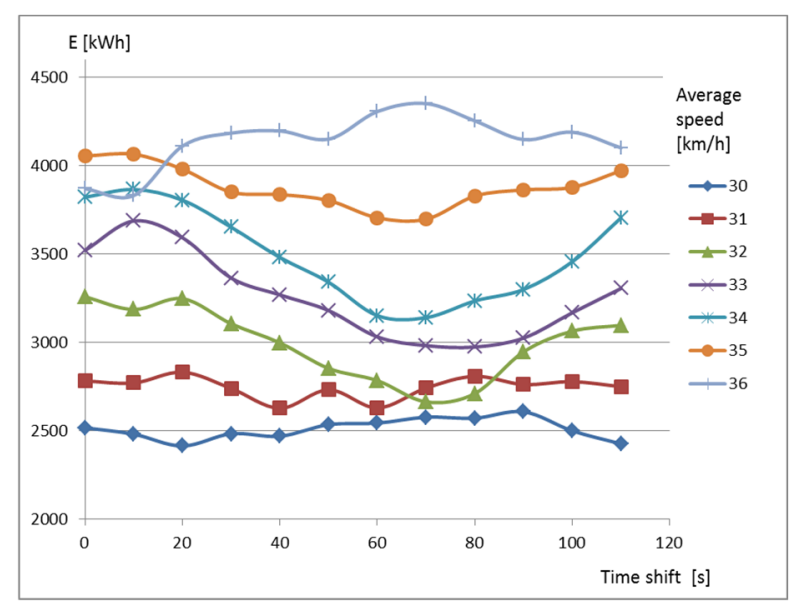

Fig. 6. Graph of energy consumption for traffic on the line with the succession time of 120 seconds.

With the average speed increase, evidently, the energy consumption increases. However, a very interesting result of the conducted simulations is that the energy consumption also depends on the shift of the traffic in both directions. There are noticeable differences reaching in some cases from about $8 \%$ (Fig. 7) to $19 \%$ (Fig. 8) presents selected, characterized by the highest variability, percentage charts of changes in energy consumption depending on the traffic shift.

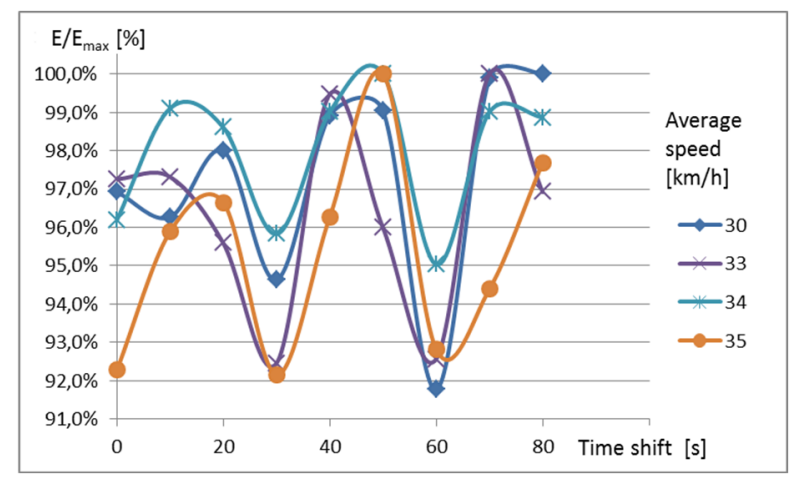

Fig. 7. Relative energy changes for line traffic with succession time of $90 \mathrm{sec}$.

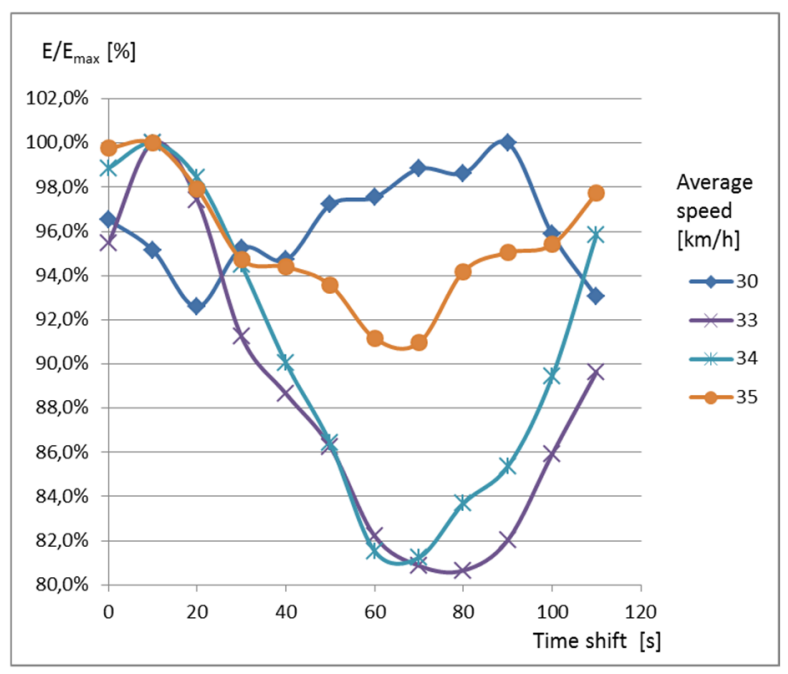

Fig. 8. Relative energy changes for line traffic with succession time of $120 \mathrm{sec}$.

The relative, minor changes in energy consumption, for the remaining average speeds and slightly different distribution of its minima, result from the fact that, at these speeds, even with changes in the travel time shifts on the line between driving directions, a sufficient number of motion situations corresponding to simultaneous recuperation braking and start up within the same electrical power section, cannot be found.

\section{Conclusions}

The article describes the case of the metro line, where modern trains, that allow energy recuperation during braking, are used. However traction substations on this line are not able to recuperate to the power network, nor are they equipped with energy storage units. On such a line of energy savings during recuperation will arise only if within the same power section, at the same time, one of the trains will be braking while the other will start up. The simulation results presented in the article indicate that it is possible to achieve savings in the traction energy consumption on the metro line by organizing traffic on the line based on adjustment of the time shift of deploying trains into traffic. Obviously, the savings achieved in above mentioned way are lower than in the case of systems enabling the return of energy to the power utility grid or equipped with energy storage units. However, these savings are achieved practically without investment, only by changing the timetable of trains.

The results presented in this paper were obtained with the omission of electricity consumption by metro trains for non-traction needs. Thus the relative energy savings are expected to be slightly lower than presented. Presented results are only valid for specified metro line. Simulation results are influenced by such factors as location of stations, vertical profile of line, traffic control system etc. For every metro line the calculations should be provided individually with mentioned factors taken under consideration. However, it should be expected that there exists time shift between vehicles moving in opposite directions which gives energy savings without additional investments in line infrastructure. 


\section{References}

1. R. Barrero, J. Mierlo, X. Tackoen. Energy Savings in Public Transport. IEEE Vehicular Technology Magazine (2008)

2. W. Gunselmann. Technologies for increased energy efficiency in railway systems. in Proc. EPE 2005, Dresden. [CD-Rom] (2005)

3. A. Szelag, Z. Drążek, T. Maciołek. Elektroenergetyka miejskiej trakcji elektrycznej. Instytut NaukowoWydawniczy „Spatium” (2017)

4. W.S Lin, J.W. Sheu. Optimization of Train Regulation and Energy Usage of Metro Lines Using an AdaptiveOptimal-Control Algorithm. IEEE Transactions on Automation Science and Engineering, vol. 8, no. 4, pp.855-864 (2011)

5. N. Zhao, C. Robert, S. Hillmansen, G. Nicholson. $A$ Multiple Train Trajectory Optimization to Minimize Energy Consumption and Delay. IEEE Transactions on Intelligent Transportation Systems, vol. 16, no. 5,pp.2363-2372 (2015)

6. A. Szelag, P. Gorczyca. An Algorithm of a Tram Running Cycle Forecasting for Purposes of Energy Consumption Calculations. 8th International Conference "Modern Electric Traction in Integrated XXIst Century Europe" Warsaw (2007)

7. H. Karbowiak, S. Barański, K. Bergiel. Polskie systemy SOP bezpiecznego prowadzenia pociagu na liniach metra. TTS Technika Transportu Szynowego, nr 1-2 s.52-56 (2014)

8. J. Czucha, K. Karwowski, M. Mizan, P Pazdro: Efektywność odzysku energii hamowania elektrodynamicznego $w$ komunikacji miejskiej. Przegląd Elektrotechniczny. R. 80, nr 10/2004, s. 1016-1019 (2004) 